\title{
LIST OF LETTERS
}

1. May 27

2. May $30-31$

3. June $8-10$

4. June $13-16$

5. June 29-July 1

6. July $5-7$

7. September 27

8. October 3

9. October 17

10. October 23

11. October 28

12. November 8

13. November 14

14. December 1

15. December 5

16. December 9

17. December 10
1796

Samuel Taylor Coleridge $\quad 3$

Coleridge

Coleridge

Coleridge

Coleridge

Coleridge

Coleridge

Coleridge

Coleridge

Coleridge

Goleridge

Coleridge

Coleridge

Coleridge

Coleridge

Coleridge

Coleridge

1797

18. January 2

19. January 7-10

20. January 16

21. February 5-6

22. February 13

23. April 7

24. April 15

25. June 12

26. June 24

27. June 29

28. July 19 or 26

29. August 24

30. September ?20
Coleridge

Coleridge

Coleridge

Coleridge

Coleridge

Coleridge

Coleridge

Coleridge

Coleridge

Coleridge

Coleridge

Coleridge

Coleridge
80

85

91

94

100

105

106

110

112

113

117

118

120 
1798

31. January

32. January 28

33. Ca. May 23-June 6

34 . July 28

35. Early to mid-August

36. August 13 or 23

37. October 18

38. October 29

39. November 3

40. November 8

41. November 13

42. November 20

43. November 20

44. November 28

45. December 27

46. January 21

47. January 23

48. March 15

49. March 20

50. April 23

51. September or October

52. October 31

53. Mid-December

54. December 17

55. December 28

56. December 30

57. January 23

58. February 8

59. February 18

60. March 1

61. March 12

62. March 17

63. April 5

64. April ca. 5-10

65. Mid-April?
Marmaduke Thompson

124

Coleridge

125

Coleridge

128

Robert Southey $\quad 130$

Robert Lloyd 133

Robert Lloyd 134

Southey

136

Southey

Southey

Southey

137

140

141

Robert Lloyd 144

Robert Lloyd $\quad 145$

Southey

Southey

Southey

148

150

154

1799

Southey

156

Southey

158

Southey

161

Southey

164

Robert Lloyd

168

170

171

173

175

176

178

1800

Coleridge

180

Manning

181

Manning

185

Manning

187

Mrs. Charles Lloyd, the elder

189

Manning

189

Manning

191

Coleridge

192

Manning 
69. May 20

Manning

70. June 1

Manning

208

71. June 8

Manning

208

72. July

73. July

74 . July 22

John Mathew Gutch

211

Manning

213

Robert Lloyd 213

75. July 28

Coleridge

215

76. August 6

Coleridge

216

77. August 9

Manning

221

78. August 11

Manning

222

79. August 14

Coleridge

224

80. August 21

Manning

228

81. August 23

Manning

230

82. August 26

Coleridge

233

83. September 22

Manning

237

84. October 9

Coleridge

239

85. October 16

Manning

241

86. November 3

Manning

243

87. November 29

Manning

247

88. December 4

William Godwin

249

89. December 10

Godwin

250

90. December 13

Manning

251

91. December 14

Godwin

255

92. December ?15

Godwin

256

93. December 15

Manning

258

94. December ?19

Manning

260

95. December ?19

Manning

261

96. December 27

Manning

262

1801

97. January ?24

Charles Lloyd, the younger

264

William Wordsworth 265

98. January 30

Manning

100. February 7

Robert Lloyd

270

101. February 15

Manning

272

102. February 27 ?

Manning 
